\title{
Real-Time Three-Dimensional Echocardiography and Myocardial Strain: Ready for Use in Clinical Practice
}

\author{
Frederico Jose Neves Mancuso ${ }^{\circ}$ \\ Universidade Federal de São Paulo - Escola Paulista de Medicina - Cardiologia e Medicina de Urgência, São Paulo, SP - Brazil \\ Short Editorial related to the article: 3-Dimensional Echocardiography and 2-D Strain Analysis of Left Ventricular, Left Atrial and Right \\ Ventricular Function in Healthy Brazilian Volunteers
}

The ability of echocardiography to quantify volumes and to evaluate the contractile function of cardiac chambers has evolved greatly in recent years, particularly due to the development of real-time three-dimensional echocardiography (echo3D) and the possibility myocardial deformation (Strain) analysis by the speckle tracking technique. ${ }^{1-3}$

Unlike two-dimensional echocardiography, where geometric inferences and mathematical calculations are required, the echo3D allows direct measurement of ventricular and atrial volumes, from which function data such as left and right ventricular ejection fraction, and left atrial function, including total emptying fraction and active emptying fraction parameters. ${ }^{4-7}$

In addition, left ventricular ejection fraction by echo3D proved to be a better prognostic parameter than the ejection fraction obtained by two-dimensional imaging. ${ }^{8}$ Furthermore, echo3D has better reproducibility and correlation with cardiac magnetic resonance than two-dimensional echocardiography. ${ }^{1,9,10}$

More recently, the speckle tracking technique for the measurement of myocardial deformation (Strain) has been developed. The strain is a novel parameter for the assessment of left and right ventricular and atrial contractile function. ${ }^{1,3}$

Myocardial strain is a parameter that seems to change before ejection fraction in several diseases that may evolve with impairment of systolic ventricular function, including cardiomyopathies, valvular heart disease, cardiotoxicity induced by chemotherapy, pulmonary hypertension, among others, and it has prognostic value in different conditions. ${ }^{1,3,11-13}$

\section{Keywords}

Ventricular Function, Left; Echocardiography, ThreeDimensional; Strain; Speckle Tracking; Reference Values.

Mailing Address: Frederico Jose Neves Mancuso •

Universidade Federal de São Paulo - Escola Paulista de Medicina - Cardiologia

- Rua Botucatu, 720. Postal Code 04124-000, São Paulo, SP - Brazil

E-mail: fredmancuso@uol.com.br

DOI: $10.5935 / a b c .20190179$
It is essential to have reference values to the use of these new technologies in clinical practice. International guidelines suggest some reference values, but they are based on few studies. ${ }^{1-3,6,14}$ More recently, the European Association of Cardiovascular Imaging conducted a multicenter study that included 440 subjects to determine real-time threedimensional and Strain echocardiographic reference values for the European population. ${ }^{6}$

Thus, the study published by Saraiva et al. ${ }^{15}$ in this issue has great importance in the Brazilian scenario, since the reference values from international publications are not always appropriate for use in the Brazilian population, which has peculiar ethnic distribution and miscegenation. ${ }^{15}$

The authors were concerned with selecting a group of individuals that were representative of the Brazilian population, including a population with an ethnic distribution similar to that observed in the IBGE demographic census. ${ }^{15}$ Also noteworthy is the assessment of sorology for Chagas in all individuals.

The reference values were determined for different parameters obtained by three-dimensional echocardiography, including diastolic and systolic ventricular volumes, as well as the left ventricular ejection fraction and the different left atrial volumes throughout the cardiac cycle, allowing to determine their total, passive and active emptying fractions. ${ }^{15}$

Regarding the parameters derived from speckle tracking, the reference value of the global left ventricular longitudinal strain was determined - the most reliable parameter and used to evaluate myocardial deformation ${ }^{1,3}$ - as well as the radial strain and circumferential strain of this chamber. In addition, it was determined the right ventricular global and free wall Strain. ${ }^{15}$

In addition, normal values for the different atrial strains throughout the cardiac cycle and left ventricular basal and apical rotation, twist, untwist, and torsion were determined. ${ }^{15}$

Considering the use in clinical practice of values between two below and above average standard deviations as normal values, we can conclude that Brazilian echocardiography laboratories can already implement these new reference values for the Brazilian population when using the new echocardiographic techniques, without having to use reference values obtained in other populations. 


\section{References}

1. Kalogeropoulos AP, Georgiopoulou VV, Gheorghiade M, Butler J. Echocardiographic evaluation of left ventricular structure and function: new modalities and potential applications in clinical trials. J Card Fail. 2012;18(2):159-72.

2. Lang RM, Badano LP, Tsang W, Adams DH, Agricola E, Buck T, et al. EAE/ASE recommendations for image acquisition and display using three-dimensional echocardiography. J Am Soc Echocardiogr. 2012;25(1):3-46.

3. Mor-Avi V, Lang RM, Badano LP, Belohlavek M, Cardim NM, Derumeaux G, et al. Current and evolving echocardiographic techniques for the quantitative evaluation of cardiac mechanics: ASE/EAE consensus statement on methodology and indications endorsed by the Japanese Society of Echocardiography. J Am Soc Echocardiogr. 2011;24(3):277-313.

4. Mancuso FJ, Almeida DR, Moisés VA, Oliveira WA, Mello ES, Poyares D, Tufik S, Carvalho AC, Campos O. Left atrial dysfunction in chagas cardiomyopathy is more severe than in idiopathic dilated cardiomyopathy: a study with real-time three-dimensional echocardiography. J Am Soc Echocardiogr. $2011 ; 24(5): 526-32$

5. Ancona R, Comenale Pinto S, Caso P, D'Andrea A, Di Salvo G, Arenga F, et al. Left atrium by echocardiography in clinical practice: from conventional methods to new echocardiographic techniques. Scientific World Journal. 2014;2014:451042.

6. Bernard A, Addetia K, Dulgheru R, Caballero L, Sugimoto T, Akhaladze N, et al. 3D echocardiographic reference ranges for normal left ventricular volumes and strain: resultsfrom the EACVI NORRE study. Eur Heart J Cardiovasc Imaging. 2017;18(4):475-83.

7. Mancuso FJ, Moisés VA, Almeida DR, Poyares D, Storti LJ, Oliveira WA et al. Left atrial volume determinants in patiets with non-ischemic dilated cardiomyopathy. Arq Bras Cardiol. 2015;105(1):65-70.

8. Mancuso FJN, Moises VA, Almeida DR, Poyares D, Storti LJ, Brito FS, et al. Prognostic value of real-time three-dimensional echocardiography compared to two-dimensional echocardiography in patients with systolic heart failure. Int J Cardiovasc Imaging. 2018;34(4):553-60.

9. Jenkins C, Bricknell K, Hanekom L, Marwick TH. Reproducibility and accuracy of echocardiographic measurements of left ventricular parameters using real-time three-dimensional echocardiography. J Am Coll Cardiol 2004;44(4):878-86

10. Keller AM, Gopal AS, King DL. Left and right atrial volume by freehand threedimensional echocardiography: in vivo validation using magnetic resonance imaging. Eur J Echocardiogr. 2000;1(1):55-65.

11. da Costa Junior AA, Ota-Arakaki JS, Ramos RP, Uellendahl M, Mancuso FJ, Gil MA, Fischer CH, Moises VA, de Camargo Carvalho AC, Campos O. Diagnostic and prognostic value of right ventricular strain in patients with pulmonary arterial hypertension and relatively preserved functional capacity studied with echocardiography and magnetic resonance. Int J Cardiovasc Imaging. 2017;33(1):39-46.

12. Luo R, Cui H, Huang D, Sun L, Song S, Sun M, Li G. Early Assessment of Right Ventricular Function in Systemic Lupus Erythematosus Patients using Strain and Strain Rate Imaging. Arq Bras Cardiol. 2018;111(1):75-81.

13. Kang Y, Wang W, Zhao H, Qiao Z, Shen X, He B. Assessment of Subclinical Doxorubicin-induced Cardiotoxicity in a Rat Model by Speckle-Tracking Imaging. Arq Bras Cardiol. 2017:109(2):132-9.

14. Lang RM, Badano LP, Mor-Avi V, Afilalo J, Armstrong A, Ernande L, et al. Recommendations for cardiac chamber quantification by echocardiography in adults: an update from the American Society of Echocardiography and the European Association of Cardiovascular Imaging. J Am Soc Echocardiogr. 2015;28(1):1-39.e14.

15. Saraiva RM, Scolin EMB, Pacheco NP, Bouret ME, Mediano MPF, Holanda MT, et al. 3-Dimensional Echocardiography and 2-D Strain Analysis of Left Ventricular, Left Atrial and Right Ventricular Function in Healthy Brazilian Volunteers. Arq Bras Cardiol. 2019; 113(5):935-945. 